\title{
The influence of maternal body mass index and physical activity on select cardiovascular risk factors of preadolescent Hispanic children
}

\author{
Basil A Alhassan ${ }^{1}$, Ying Liu ${ }^{1}$, Deborah Slawson ${ }^{2}$, Jonathan M Peterson ${ }^{3}$, Jo-Ann Marrs ${ }^{4}$, William A Clark ${ }^{5}$ \\ Arsham Alamian ${ }^{\text {Corresp. } 6}$ \\ 1 Department of Biostatistics and Epidemiology, College of Public Health, East Tennessee State University, Johnson City, TN, United States \\ 2 Department of Community and Behavioral Health, College of Public Health, East Tennessee State University, Johnson City, TN, United States \\ 3 Department of Health Sciences, College of Public Health, East Tennessee State University, Johnson City, TN, United States \\ 4 College of Nursing, East Tennessee State University, Johnson City, TN, United States \\ 5 College of Clinical and Rehabilitative Health Sciences, East Tennessee State University, Johnson City, TN, United States \\ 6 Department of Biostatistics and Epidemiology, College of Public Health, East Tennessee State University, Johnson City, TN, United States of America \\ Corresponding Author: Arsham Alamian \\ Email address: alamian@etsu.edu
}

Background. Maternal obesity and physical inactivity have been identified as correlates of overweight and obesity and physical inactivity in older preadolescents; however, no study has explored this relationship in Hispanic preadolescents. Furthermore, the relation between maternal physical activity (PA) and blood pressure (BP) in Hispanic preadolescents has not been examined. Purpose. This study aimed to assess the associations between Hispanic mothers' PA and body mass index (BMI) and their preadolescents' PA, screen time, BP, and BMI. Methods. Data of 118 mother-child (aged 2 to 10 years) dyads enrolled in a cross-sectional study of metabolic syndrome in Hispanic preadolescents at a community health center in Johnson City, TN were used. Parent and child questionnaires were used to ascertain mothers' BMI and PA and preadolescents' PA and screen time. Preadolescents' height, weight, and BP were measured. Multiple logistic regression was used to examine the association between child and maternal variables, adjusting for mother's education and the child's sex and age. Results. Pradolescents of obese mothers were more likely than preadolescents of mothers with normal weight to engage in less than three days of at least 60 minutes of vigorous PA per week (OR: 6.47: 95\% Cl: 1.61-26.0). Preadolescents whose mothers did not engage in moderate PA were more likely to engage in less than three days of at least 60 minutes of vigorous PA per week (OR: 2.92, Cl: 1.18-7.24); and have elevated BP (OR: 2.50, 95\% Cl: 1.02-4.53) than preadolescents whose mothers engaged in moderate PA. Discussion. Our results show a negative relationship between maternal obesity and preadolescent PA, and a positive relationship between lower maternal PA and elevated BP and lower PA in Hispanic 
preadolescents. This suggests that interventions aimed at improving Hispanic preadolescents' PA and BP may use maternal PA and maternal BMI (for preadolescent PA) as a modification strategy to improve health in Hispanic preadolescents. 


\section{The influence of maternal body mass index and physical activity on select}

\section{2 cardiovascular risk factors of preadolescent Hispanic children}

3 Basil A. Alhassan, DrPH,${ }^{1}$ Ying Liu, PhD,${ }^{1}$ Deborah L. Slawson, $\mathrm{PhD},{ }^{2}$ Jonathan M. Peterson,

4 PhD, ${ }^{3}$ Jo-Ann Marrs, EdD, ${ }^{4}$ William A. Clark, PhD, ${ }^{5}$ Arsham Alamian, $\mathrm{PhD}^{1 *}$

$5 \quad{ }^{1}$ Department of Biostatistics and Epidemiology, College of Public Health, East Tennessee State

6 University, Johnson City, TN;

$7 \quad 2$ Department of Community and Behavioral Health, College of Public Health, East Tennessee

8 State University, Johnson City, TN;

$9{ }^{3}$ Department of Health Sciences, College of Public Health, East Tennessee State University, 10 Johnson City, TN;

$11{ }^{4}$ College of Nursing, East Tennessee State University, Johnson City, TN;

$12{ }^{5}$ College of Clinical and Rehabilitative Health Sciences, East Tennessee State University,

13 Johnson City, TN

$14{ }^{*}$ Corresponding author:

15 Arsham Alamian, PhD, MSc, MACE

16 Department of Biostatistics and Epidemiology

17 College of Public Health, East Tennessee State University

18 PO Box 70259

19 Johnson City, TN 37614

20 Phone: (423) 439-4428

21 Fax: (423) 439-6491

22 Email: alamian@etsu.edu 
23 Abstract

24 overweight and obesity and physical inactivity in older preadolescents; however, no study has explored this relationship in Hispanic preadolescents. Furthermore, the relation between maternal physical activity (PA) and blood pressure (BP) in Hispanic preadolescents has not been examined.

Purpose. This study aimed to assess the associations between Hispanic mothers' PA and body mass index (BMI) and their preadolescents' PA, screen time, BP, and BMI.

Methods. Data of 118 mother-child (aged 2 to 10 years) dyads enrolled in a cross-sectional study of metabolic syndrome in Hispanic preadolescents at a community health center in Johnson City, TN were used. Parent and child questionnaires were used to ascertain mothers' BMI and PA and preadolescents' PA and screen time. Preadolescents' height, weight, and BP were measured. Multiple logistic regression was used to examine the association between child and maternal variables, adjusting for mother's education and the child's sex and age.

Results. Preadolescents of obese mothers were more likely than preadolescents of mothers with normal weight to engage in less than three days of at least 60 minutes of vigorous PA per week (OR: 6.47: 95\% CI: 1.61-26.0). Preadolescents whose mothers did not engage in moderate PA were more likely to engage in less than three days of at least 60 minutes of vigorous PA per week (OR: 2.92, CI: 1.18-7.24); and have elevated BP (OR: 2.50, 95\% CI: 1.02-4.53) than preadolescents whose mothers engaged in moderate PA.

44 Discussion. Our results show a negative relationship between maternal obesity and preadolescent PA, and a positive relationship between lower maternal PA and elevated BP and lower PA in 
46 Hispanic preadolescents. This suggests that interventions aimed at improving Hispanic

47 preadolescents' PA and BP may use maternal PA and maternal BMI (for preadolescent PA) as a

48 modification strategy to improve health in Hispanic preadolescents. 
50

51

52

\section{Introduction}

Physical inactivity, elevated blood pressure (BP), and overweight and obesity track from childhood to adulthood (McGill, McMahan, \& Gidding, 2008; Napoli et al., 2006), and increase the risk of cardiovascular diseases such as heart disease and stroke (Mozaffarian et al., 2016). According to the 2008 Physical Activity Guidelines for Americans (U.S. Department of Health and Human Services, 2008), children should engage in at least one hour of physical activity (PA) per day, including at least three days of moderate-to-vigorous intensity aerobic activity. Adequate PA in childhood can prevent obesity and elevated blood pressure (Expert Panel on Integrated Guidelines for Cardiovascular Health and Risk Reduction in Children and Adolescents; National Heart, Lung, and Blood Institute, 2011). Despite evidence of the cardiovascular benefits of adequate PA and the detrimental effects of a sedentary lifestyle, a significant number of U.S children and adolescents do not meet national recommendations. Per the 2013 Youth Risk Behavior Survey (Kann et al., 2014), 15.2\% of high school students nationwide did not meet the recommendation of at least 60 minutes of PA in the past week; 41.3\% spent three or more hours playing computer or video games un-related to school work; and $32.5 \%$ spent three or more hours watching television per day. Only $27.1 \%$ of high school students nationwide met the PA guidelines. Of students in kindergarten through the $12^{\text {th }}$ grade nationwide, only $29.4 \%$ attended structured daily physical education classes in school (Kann et al., 2012).

Hypertension in children is defined as average systolic (SBP) and/or diastolic (DBP) blood pressure higher than or equal to the $95^{\text {th }}$ percentile for sex, age, and height on three or more repeated measurements (National High Blood Pressure Education Program Working Group on High Blood Pressure in Children and Adolescents, 2004). Elevated BP, or prehypertension, 
73 refers to average SBP or DBP higher than or equal to the $90^{\text {th }}$ percentile, but less than the $95^{\text {th }}$

74 percentile. Although from 2003-2004 to 2011-2012, the prevalence of elevated BP among 8-17-

75 year-old U.S children decreased from 3.1\% to $1.6 \%$, the prevalence of elevated BP was $11.5 \%$

76 for Hispanic children versus 9.4\% for non-Hispanic White children in 2011-2012 (Kit et al.,

77 2015). Further, about eighteen percent (17.7\%) of children 12-to-19 years old have either poor or

78 intermediate scores on the American Heart Association's BP metric of cardiovascular health

79 (Mozaffarian et al., 2016). Routine measurement of BP during health care visits is recommended

80 for children three or more years old (Chobanian et al., 2003; National Heart, Lung, 2011).

81

Overweight and obesity remain a major public health problem. Childhood overweight

and obesity prevalence rates are high across all racial groups; however, Hispanic children experience higher prevalence of obesity (Falkner \& Cossrow, 2014; Kit et al., 2015; Nguyen, Kit, \& Carroll, 2015) as compared to their non-Hispanic White peers. Hispanic children are also more likely to experience earlier onset of obesity and be severely obese (Mozaffarian et al., 2016) as compared to their non-Hispanic White peers. From 2003-2004 to 2013-2014, the prevalence of obesity among 2-19-year-old U.S children decreased slightly from $17.1 \%$ to 16.9\%, among 2-19-year-old Mexican American females, it increased from $16.1 \%$ to $24.2 \%$, and among 2-19-year-old Mexican American males, it decreased from 22.0\% to 19.5\% (Cheryl, Carroll, \& Ogder, 2016). Recommended strategies to prevent obesity include programs to increase PA in the community, increase consumption of fruits and vegetables, environmental approaches to improve transportation and use of land, as well as early care and education at schools (Centers for Disease and Prevention, 2018).

A positive energy balance resulting from a set of risk factors including poor diet, physical inactivity, genes, aging and ethnicity underlie the development of overweight and obesity (Kelly 
96

97

et al., 2013). A similar set of risk factors including obesity, high dietary salt intake, male gender, older age, and ethnicity, drive the development of hypertension in preadolescents (Kelly et al., 2013). In addition to these established risk factors, many studies (Fuemmeler, Anderson, \& Mâsse, 2011; Ruiz e al., 2011; Whitaker etal., 1997) have found an association between maternal PA and body mass index (BMI), and obesity and hypertension in older children (Durand et al., 2011; Gordon-Larsen et al., 2006; Rosendranz \& Dzewaltowski, 2011; Sallis et al., 2009a; Sallis, et al., 2009b; Van Den Berg et al., 2013). However, no study has examined the influence of mother's PA or BMI on Hispanic preadolescents' BMI, PA and BP.

Therefore, this study tests two related hypotheses: First, mothers who self-report to be less physically active are less likely to self-report that their preadolescent children are physically active, and that their preadolescent children are more likely to self-report as having more screen time. Second, an increased maternal weight is associated with increased preadolescent weight and BP in Hispanic children. It is important to understand the relation between the maternal and child health characteristics among Hispanics in order to inform the development of public health interventions for the large and growing Hispanic community in Tennessee.

\section{Materials \& Methods}

\section{Data Source and Participants}

Data for this study came from a cross-sectional pilot study of metabolic syndrome in Hispanic preadolescents, ages 2-10 years, who presented for well-child care at a community health center in Johnson City, TN, from June 2015 to June 2016, accompanied by their mothers. No participant in the original study reported a pre-existing diagnosis of metabolic syndrome. The 
118 study was reviewed and approved by the Institutional Review Board of the East Tennessee State

119 University (IRB\#: 0414.16s).

Of the original 150 preadolescents, 21 of a set of 21 pairs of siblings and four of a set of

121 two sets of three siblings were randomly eliminated. Siblings were included in the initial sample

122 because basic science researchers on the multidisciplinary team were interested in studying

123 siblings. Two preadolescents with BMI below the fifth percentile were also excluded because of

124 this study's focus on normal BMI, overweight and obesity. An additional five preadolescents

125 who did not have BMI and/or BP data were removed. The final analytic sample consisted of 118

126 preadolescents.

127

128

129

130

131

132

133

134

135

136

137

138

139

140

\section{Data Collection Methods}

A pediatric nurse identified potentially eligible mother-child dyads two days before the wellchild visit. Inclusion criteria for preadolescents were: being 2-10 years of age; Hispanic, as defined by the U.S. Census Bureau; and not having a serious physical or mental illness. Motherchild dyads were provided written and oral information on the study protocols and purpose and thereafter were requested to provide written voluntary informed consent. Children seven years or older and mothers were required to provide written informed consent to proceed with the study.

An experienced research assistant, proficient in written and spoken English language and Spanish, was trained in using a set of child and parent questionnaires to collect child and parent sociodemographic, PA, and screen time data. Mother's height and weight were reported in the parent questionnaire. Questionnaires were administered in English or Spanish language and the mother was the respondent. A pediatric nurse practitioner measured preadolescent's height, 
141 weight and BP using standard protocols (Centers for Disease Control and Prevention, 2007). A

142 standard scale which was tested and calibrated daily for accuracy was used to measure weight to

143 the nearest 0.2 pounds; a stadiometer was used to measure height to the nearest one-eighth of an

144 inch; and auscultation with a stethoscope and a standard clinical mercury sphygmomanometer

145 was used to measure child BP after the child rested for at least five minutes.

146

147

148

149

150

151

152

153

154

155

156

157

158

159

160

161

162

163

164

\section{Outcome Measures}

Child systolic and diastolic BP percentiles were obtained from CDC blood pressure charts and categorized as: 1. normal BP (systolic or diastolic $\mathrm{BP}<90^{\text {th }}$ percentile) and 2. elevated BP (systolic or diastolic BP $>=90^{\text {th }}$ percentile) (National High Blood Pressure Education Program Working Group on High Blood Pressure in Children and Adolescents, 2004). Child BMI percentiles were calculated using the 2000 CDC growth charts (Centers for Disease Control and Prevention, 2000). Participants were grouped as: 1 . underweight (less than $5^{\text {th }}$ percentile), 2. Healthy weight $\left(5^{\text {th }}-84^{\text {th }}\right.$ percentiles $), 3$. Overweight $\left(>=85^{\text {th }}-94^{\text {th }}\right.$ percentiles $)$, and 4 . obese $(>=$ 95 ${ }^{\text {th }}$ percentile) (Centers for Disease Control and Prevention, 2000). Because of the study's small sample size, the remaining three BMI categories were collapsed into two categories: 1. normal BMI preadolescents ( $5^{\text {th }}$ through $84^{\text {th }}$ percentile) and 2. Overweight and obese preadolescents which included preadolescents with BMI from $85^{\text {th }}$ percentile and above, for age and sex. Child PA was assessed by the question: "during the past 7 days, on how many days was your child physically active for a total of at least 60 minutes per day? Add up all the time he/she spent in any kind of physical activity that increased his/her heart rate and made him/her breathe hard some of the time" (National Center for Health Statistics, 2013). The responses ranged from 0 to 7 days. We categorized the number of days of preadolescents' PA in a week using recommended guidelines (U.S. Department of Health and Human Services, 2008); however, 
165 because of the small sample size and distribution of responses, the variable was categorized as:

166 1. $<3$ days of vigorous PA per week and 2. $>=3$ days of vigorous PA per week.

Child screen time (TV or video) was assessed by the question: "over the past 30 days, on

168

169

170

171

172

173

174

175

176

177

178

179

180

181

182

183

184

185

186

187

188

\section{Mother's BMI and Physical Activity} average how many hours per day did your child sit and watch TV or videos" (National Center for Health Statistics, 2013). The responses ranged from 0 to 8. Based on the American Academy of Pediatrics' recommendation, the variable was categorized as: $1 .<=2$ hours per day and $2 .>2$ hours per day (American Academy of Pediatrics, 2010).

Mother's BMI was calculated and categorized as: 1 . healthy $\left(18.5 \mathrm{~kg} / \mathrm{m}^{2}<=\mathrm{BMI}<=24.9\right.$ $\left.\mathrm{kg} / \mathrm{m}^{2}\right) ; 2$. Overweight $\left(25 \mathrm{~kg} / \mathrm{m}^{2}<=\right.$ BMI $\left.<=29.9 \mathrm{~kg} / \mathrm{m}^{2}\right) ;$ and 3 . Obese $\left(\mathrm{BMI}>=30 \mathrm{~kg} / \mathrm{m}^{2}\right)$ (Centers for Disease Control and Prevention, 2015). Mother's PA was assessed by the question: "in a typical week, do you do any moderate-intensity sports, fitness, or recreational activities which cause a small increase in breathing or heart rate such as brisk walking, bicycling, swimming, or golf for at least 10 minutes continuously?" (National Center for Health Statistics, 2013). The responses were: 1 . Yes or 2. No.

\section{Sociodemographic Measures}

Child age was computed as completed years from reported date of birth. Child sex was reported as either male or female. Age was categorized as: 1. 2-5 years; and 2. 6-10 years to reflect developmental, biological and social differences by age. Educational attainment has been used as a proxy for socioeconomic status (Hendrie et al., 2013) because income levels increase with 
189 higher educational attainment. Mother's education was used as a proxy for mother's

190 socioeconomic status and categorized as: 1 . less than $9^{\text {th }}$ grade; $2.9^{\text {th }}-11^{\text {th }}$ grade; 3 . High school

191 graduate/GED or equivalent; and 4. Some college, Associate Academic degree or above.

192

193

194

195

196

197

198

199

200

201

202

203

204

205

206

207

208

209

210

211

212

\section{Statistical Analyses}

Chi-squared and Fisher's exact tests were used to examine differences in the prevalence of preadolescents' elevated BP, being overweight or obese, excessive screen time, and low PA levels by sociodemographic characteristics, as well as the relationship between mother's BMI status and PA levels, and preadolescents' elevated BP, being overweight or obese, excessive screen time, and low PA levels. Chi-squared and Fisher's exact tests were also used to examine bivariate associations between preadolescents' BP, BMI status, screen time, and PA.

Independent variables with a $P$ value $<0.20$ in univariate associations were entered in multiple logistic regression models of child's low PA levels, being overweight or obese, and elevated BP (Mickey \& Greenland, 1989; Fagerland, Hosmer, \& Bofin, 2008). Variables with a $P \geq 0.20$ were also entered one by one in the multivariable model to identify confounders. Child age, child sex, as well mother's education were included in all models as they are sociodemographic variables universally considered as potential confounders. Alpha less than 0.05 was set as the threshold for statistically significant associations. Data analysis was performed in statistical analyst system (SAS version 9.4). Outcome and independent variables were treated as categorical variables for ease of interpreting results from logistic regression analysis. Regrouping within each variable was necessitated by the small sample size of this study.

\section{Results}


213 All mothers and children in the study identified as Hispanic. The mean age of the preadolescents

214 was 6.36 years $(S D=2.75)$ and half were female (Table 1). Children subjects were identified as

$21576.3 \%$ Mexican-American, and 23.7\% as of other Hispanic origin (Puerto Rican, Guatemalan,

216 Ecuadorian and Columbian). About eighty nine percent (88.9\%) of mothers had no education

217 beyond high school or the equivalent of high school (Table 1).

About a third (31.4\%) of preadolescents had elevated BP, and about 4 out of $10(40.7 \%)$

219

220

221

222

223

224

225

226

227

228

229

230

231

232

233

234

235

Two-to-five-year-old preadolescents had a higher prevalence of elevated BP compared to 6-to-10-year-olds (45.7\% vs. $22.2 \%, p=0.007)$ (Table 1). Likewise, preadolescents whose mothers did not engage in moderate PA tended to have a higher prevalence of elevated BP (38.7\% vs. $23.2 \%, p=0.07$ ) (Table 2); and higher prevalence of engaging in less than three days of at least 60 minutes of vigorous PA per week, (33.9\% vs. 19.4\%, $p=0.072)$ (Table 2), than preadolescents whose mothers engaged in moderate PA. Preadolescents whose mothers did not engage in moderate PA tended to have a higher prevalence of being overweight/obese than preadolescents whose mothers engaged in moderate PA, $(46.8 \%$ vs. $33.9 \%, p=0.08)$. Table 3 shows bivariate associations between preadolescent's PA, screen time, BP and BMI. Preadolescents' BMI and BP were significantly associated $(p=0.046)$.

In adjusted multiple logistic regression, preadolescents of obese mothers were 6.47 times more likely than preadolescents of mothers with normal BMI to engage in less than three days of at least 60 minutes of vigorous PA per week (95\% CI: 1.61-26.0) (Table 4). Preadolescents whose mothers did not engage in moderate PA were 2.92 times more likely to engage in less than 
236 three days of at least 60 minutes of vigorous PA per week (95\% CI: 1.18-7.24); and 2.5 times

237 more likely to have elevated BP (95\% CI: 1.02-4.53) than preadolescents whose mothers

238 engaged in moderate PA (Table 4).

\section{Discussion}

241

242 In this study, we found that about four out of every ten preadolescents were overweight or obese $243(40.7 \%)$, and about three out of every ten had elevated BP (31.4\%). The study sample's

244 prevalence of being overweight/obese is similar to national estimates for Hispanic children

245 (Ogden et al., 2014). Estimates of the prevalence of elevated BP in children are few and difficult 246 to compare. In a large cohort study of 3-to-18-year-old children presenting for well-child care,

247 Hansen, Gunn, and Kaelbar (2007) determined the prevalence of elevated BP to be 7.0\%. A 248 study by Ma, Zhang, and Xi (2016) using NHANES 2013-2014 data reported the prevalence of 249 elevated BP in 8-to-17-year-olds to be 7.0\%. Kit et al. (2015) also using NHANES data 250 estimated the prevalence of elevated BP in 8-to-17-year-old children to be $11.0 \%$ in 2011-2012. 251 The prevalence of elevated BP in this study exceeds estimates from these previous studies. One 252 explanation is the low socioeconomic status of participants. About $89 \%$ of mothers had only a 253 high school education or less. Low socioeconomic status is associated with significantly higher 254 obesity and hypertension (Brummett et al., 2011; Van Den Berg et al., 2013). than preadolescents of mothers with normal BMI to engage in less than three days of at least 60 minutes of vigorous PA per week; and preadolescents whose mothers did not engage in moderate

258 PA were 2.92 times more likely to engage in less than three days of at least sixty minutes of 
259 vigorous PA than preadolescents whose mothers engaged in moderate PA. Our findings comport

260 with previous studies which have found strong mother-child correlations in PA and a strong

261 association between maternal obesity and child PA. In a study of 3-to-5-year-old Hispanic

262 preadolescents and their mothers at a local community center in Nashville, TN, Ruiz et al. (2011)

263 observed strong mother-child correlation in sedentary behavior and moderate PA; Fuemmeler,

264 Anderson, and Masse (2011) found a high correlation of moderate-to-vigorous PA (MVPA)

265 between mothers and their preadolescents. Rosendranz and Dzewaltowski (2011) found that

266 mother-child shared PA was negatively associated with child BMI percentile, and that maternal

267 BMI was positively correlated with child BMI. The same study evaluated the effects of PA-

268 related-parenting behaviors such as encouragement, transporting the child for PA and watching

269 the child do PA. Of all PA-related-parenting behaviors, PA encouragement had the strongest

270 correlation with child PA.

271 We also found that preadolescents whose mothers did not engage in moderate PA were

2722.5 times more likely to have elevated BP than preadolescents whose mothers engaged in

273 moderate PA. Physical inactivity and overweight are risk factors for elevated BP in

274 preadolescents (Ewald \& Haldeman, 2016; Gopinath et al., 2014; Leary et al., 2008). However,

275 after controlling for child PA, and BMI, preadolescents whose mothers did not engage in

276 moderate PA remained significantly more likely to have elevated BP than preadolescents whose

277 mothers engaged in moderate PA. To the best of our knowledge, this is the first study to report a

278 significant association between maternal PA and child BP in Hispanic preadolescents,

279 independent of child's BMI and PA. 
This study has some limitations. The sample size was relatively small; hence the study

282

283

284

285

286

287

288

289

290

291

292

293

294

295

296

297

may have lacked power to reach significance for some of the associations. Second, being a crosssectional study of predominantly Mexican-Americans, our findings may not be generalizable to all Hispanic preadolescents and do not indicate causality. Longitudinal studies are needed for further investigating the correlation between maternal and preadolescent factors examined in this study. Third, our inability to control for diet may potentially confound our findings. However, these weaknesses should be weighed against the strengths of this study. To the best of our knowledge, this is the first study which has assessed the prevalence and sociodemographic correlates of elevated BP in Hispanic preadolescents in Tennessee.

\section{Conclusions}

The prevalence of overweight or obesity and elevated BP among Hispanic preadolescent subjects, especially in 2-to-5-year-olds was higher than expected based on estimates from national studies (Kit et al., 2015; Ma, Zhang, \& Xi, 2016). Low maternal PA was associated with elevated BP and lower PA in preadolescents; likewise, maternal obesity was associated with lower PA in preadolescents. Our findings suggest the need for public health interventions that would encourage mothers to increase physical activity and improve weight control as a means for reducing obesity and hypertension in Hispanic preadolescents. 


\section{Acknowledgments}

299 The authors would like to thank all families who voluntarily participated in this study. 
300

301

302

303

304

305

306

307

308

309

310

311

312

313

314

315

316

317

318

319

320

\section{References}

American Academy of Pediatrics. (2010). Media Education. Pediatrics, 126(5), 1-6. https://doi.org/10.1542/peds.2010-1636

Brummett, B. H., Babyak, M. A., Siegler, I. C., Shanahan, M., Harris, K. M., Elder, G. H., Williams, R. B. (2011). Systolic blood pressure, socioeconomic status, and biobehavioral risk factors in a nationally representative us young adult sample. Hypertension, 58(2), 161166. https://doi.org/10.1161/HYPERTENSIONAHA.111.171272

Centers for Disease Control and Prevention. (2000). Pediatric Growth Reference. Retrieved January 1, 2016, from https://www.bcm.edu/bodycomplab/Flashapps/bmiVAgeChartpage.html

Centres for Disease Control and Prevention. (2007). Anthropometry procedures manual. National Health and Nutrition Examinatory Survey (NHANES), (January), 102. Retrieved January 10, 2017, from http://www.cdc.gov/nchs/data/nhanes/nhanes_07_08/manual_an.pdf

Centers for Disease Control and Prevention. (2015). Adult Obesity Facts. Overweight \& Obesity. Retrieved January 12, 2017, https:/www.cdc.gov/obesity/data/adult.html

Centers for Disease Control and Prevention. (2018). Prevention Strategies and Guidelines. Retrieved September 20, 2018, from https://www.cdc.gov/obesity/resources/strategiesguidelines.html

Cheryl, F., Carroll, M., Ogden, C. (2016). Prevalence or Overweight and Obesity Among Children and Adolescents Aged 2-19 Years: United States, 1963-1965 Through 2013-2014. Health E-Stats. 
321 Chobanian, A. V., Bakris, G. L., Black, H. R., Cushman, W. C., Green, L. A., Izzo, J. L., ...

322 Roccella, E. J. (2003). Seventh report of the Joint National Committee on Prevention,

323 Detection, Evaluation, and Treatment of High Blood Pressure. Hypertension, 42(6), 1206-

324 1252. https://doi.org/10.1161/01.HYP.0000107251.49515.c2

325 Durand, C. P., Andalib, M., Dunton, G. F., Wolch, J., Pentz, M. A. (2011). A Systematic Review

326 of Built Environment Factors Related to Physical Activity and Obesity Risk: Implications

327 for Smart Growth Urban Planning. Obesity Reviews, 12(501), e173-e182.

328 https://doi.org/10.1111/j.1467-789X.2010.00826.x.A

329 Ewald, D. R., Haldeman, L. A. (2016). Risk Factors in Adolescent Hypertension. Global

$330 \quad$ Pediatric Health, 3, 2333794X15625159. https://doi.org/10.1177/2333794X15625159

331 Fagerland, M.W., Hosmer, D.W., Bofin, A.M. (2008). Multinomial goodness-of-fit tests for

332 logistic regression models. Statistics in Medicine.27: 4238-4253.

333 Falkner, B., Cossrow, N. D. F. H. (2014). Prevalence of metabolic syndrome and obesity-

334 associated hypertension in the racial ethnic minorities of the United States. Current

335 Hypertension Reports, 16(7), 1-15. https://doi.org/10.1007/s11906-014-0449-5

336 Fuemmeler, B. F., Anderson, C. B., Mâsse, L. C. (2011). Parent-child relationship of directly

337 measured physical activity. Int J Behav Nutr Phys Act, 8(1), 17.

338 https://doi.org/10.1186/1479-5868-8-17

339

340

341

342

Gopinath, B., Hardy, L. L., Kifley, A., Baur, L. A., Mitchell, P. (2014). Activity behaviors in schoolchildren and subsequent 5-yr change in blood pressure. Medicine and Science in Sports and Exercise, 46(4), 724-729. https://doi.org/10.1249/MSS.0000000000000166

Gordon-Larsen, P., Nelson, M. C., Page, P., Popkin, B. M. (2006). Inequality in the Built 
Environment Underlies Key Health Disparities in Physical Activity and Obesity. Pediatrics, 117(2), 417-424. https://doi.org/10.1542/peds.2005-0058

Hansen, M. L., Gunn, P. W., Kaelbar, D. C. (2007). Underdiagnosis of hypertension in children and adolescents. Journal of the American Medical Association, 298(8), 874-879. https://doi.org/10.1001/jama.298.8.874.ABSTRACT

Hendrie, G., Sohonpal, G., Lange, K., Golley, R. (2013). Change in the family food environment is associated with positive dietary change in children. The International Journal of Behavioral Nutrition and Physical Activity, 10(1), 4. https://doi.org/10.1186/1479-5868-10-

Kann, L., Kinchen, S., Shanklin, S. L., Flint, K. H., Kawkins, J., Harris, W. a, .. Zaza, S. (2012). Youth risk behavior surveillance--United States, 2011. Morbidity and Mortality Weekly Report. Surveillance Summaries (Washington, D.C. : 2002), 61(4), 1-168. Retrieved from http://www.ncbi.nlm.nih.gov/pubmed/24918634

Kann, L., Kinchen, S., Shanklin, S. L., Flint, K. H., Kawkins, J., Harris, W. a, ... Zaza, S. (2014). Youth risk behavior surveillance--United States, 2013. Morbidity and Mortality Weekly Report. Surveillance Summaries (Washington, D.C. : 2002), 63 Suppl 4(4), 1-168. https://doi.org/ss6304a1 [pii]

Kelly, A. S., Barlow, S. E., Rao, G., Inge, T. H., Hayman, L. L., Steinberger, J., ... Daniels, S. R. (2013). Severe obesity in children and adolescents: Identification, associated health risks, and treatment approaches: A scientific statement from the American Heart Association. Circulation, 128(15), 1689-1712. https://doi.org/10.1161/CIR.0b013e3182a5cfb3

Kit, B. K., Kuklina, E., Carroll, M. D., Ostchega, Y., Freedman, D. S., Ogden, C. L. (2015). 
Prevalence of and trends in dyslipidemia and blood pressure among US children and adolescents, 1999-2012. JAMA Pediatrics, 169(3), 272-9. https://doi.org/10.1001/jamapediatrics.2014.3216

Leary, S. D., Ness, A. R., Smith, G. D., Mattocks, C., Deere, K., Blair, S. N., Riddoch, C. (2008). Physical activity and blood pressure in childhood: Findings from a population-based study. Hypertension, 51(1), 92-98. https://doi.org/10.1161/HYPERTENSIONAHA.107.099051

Ma, C., Zhang, T., Xi, B. (2016). Prevalence of Elevated Blood Pressure Among US Children, 2013-2014. The Journal of Clinical Hypertension, 18(10), 2013-2014. https://doi.org/10.1111/jch.12824

McGill, H. C., McMahan, C. A., Gidding, S. S. (2008). Preventing heart disease in the 21st century: Implications of the pathobiological determinants of atherosclerosis in youth (PDAY) study. Circulation, 117(9), 1216-1227. https://doi.org/10.1161/CIRCULATIONAHA.107.717033

Mickey, R.M., Greenland, S. (1989). The impact of confounder selection criteria on effect estimation. American Journal of Epidemiology.129: 125-137.

Mozaffarian, D., Benjamin, E. J., Go, A. S., Arnett, D. K., Blaha, M. J., Cushman, M., ... Turner, M. B. (2016). Heart disease and stroke statistics-2016 update a report from the American Heart Association. Circulation, 133(4), e38-e48. https://doi.org/10.1161/CIR.0000000000000350

Napoli, C., Lerman, L. O., De Nigris, F., Gossl, M., Balestrieri, M. L., Lerman, A. (2006). Rethinking primary prevention of atherosclerosis-related diseases. Circulation, 114(23), 
388

389

390

391

392

393

394

395

396

397

398

399

400

401

402

403

404

405

406

407

National Center for Health Statistics. (2013). NHANES 2013-2014 Physical Activity and Physical Fitness Questionnaire. Retrieved November 26, 2016, from https://www.cdc.gov/nchs/data/nhanes/nhanes_13_14/PAQ_H.pdf

National High Blood Pressure Education Program Working Group on High Blood Pressure in Children and Adolescents (2004). The fourth report on the diagnosis, evaluation, and treatment of high blood pressure in children and adolescents. Pediatrics, 114(2 suppl), 555576.

Nguyen, D., Kit, B., Carroll, M. (2015). Abnormal Cholesterol Among Children and Adolescents in the United States , 2011 - 2014. NCHS Data Brief, (228), 2011-2014.

Ogden, C. L., Carroll, M. D., Kit, B. K., Flegal, K. M. (2014). Prevalence of childhood and adult obesity in the United States, 2011-2012. Journal of the American Merdical Association, 311(8), 806-814. https://doi.org/10.1001/jama.2014.732

Rosendranz, R.R., Dzewaltowski, D. A. (2011). Maternal Physical-Activity-Related Parenting Behaviors May Influence Children’s Physical Activity Levels and Relative Weight. Women in Sport and Physical Activity Journal, 20(1). https://doi.org/10.1123/wspaj.20.1.3

Ruiz, R., Gesell, S. B., Buchowski, M. S., Lambert, W., Barkin, S. L. (2011). The Relationship Between Hispanic Parents and Their Preschool-Aged Children's Physical Activity. Pediatrics, 127(5), 888-895. https://doi.org/10.1542/peds.2010-1712

Sallis, J. F., Bowles, H. R., Bauman, A., Ainsworth, B. E., Bull, F. C., Craig, C. L., ... Bergman, P. (2009). Neighborhood Environments and Physical Activity Among Adults in 11 
408

409

410

411

412

413

414

415

416

417

418

419

420

421

422

423

424

425

426

427

Countries. American Journal of Preventive Medicine, 36(6), 484-490.

https://doi.org/10.1016/j.amepre.2009.01.031

Sallis, J. F., Saelens, B. E., Frank, L. D., Conway, T. L., Slymen, D. J., Cain, K. L., ... Kerr, J. (2009). Neighborhood built environment and income: Examining multiple health outcomes. Social Science and Medicine, 68(7), 1285-1293. https://doi.org/10.1016/j.socscimed.2009.01.017

U.S. Department of Health and Human Services (2008). 2008 Physical activity guidelines for Americans. President's Council on Physical Fitness \& Sports Research Digest, 9(4), 1-8. https://doi.org/10.4085/1062-6050-44.1.5

Expert Panel on Integrated Guidelines for Cardiovascular Health and Risk Reduction in Children and Adolescents; National Heart, Lung, and Blood Institute (2011). Expert Panel on Integrated Guidelines for Cardiovascular Health and Risk Reduction in Children and Adolescents. Pediatrics, 128, suppl. 5. https://doi.org/10.1542/peds.2009-2107C

Van Den Berg, G., Van Eijsden, M., Galindo-Garre, F., Vrijkotte, T. G. M., Gemke, R. J. B. J. (2013). Explaining socioeconomic inequalities in childhood blood pressure and prehypertension: The ABCD study. Hypertension, 61(1), 35-41. https://doi.org/10.1161/HYPERTENSIONAHA.111.00106

Whitaker, R. C., Wright, J. A., Pepe, M. S., Seidel, K. D., Dietz, W. H. (1997). Predicting Obesity in Young Adulthood from Childhood and Parental Obesity. New England Journal of Medicine, 337(13), 869-873. https://doi.org/10.1056/NEJM199709253371301 


\section{Table $\mathbf{1}$ (on next page)}

Sociodemographic characteristics of preadolescents by cardiovascular risk factors $(\mathrm{N}=118)^{\mathrm{a}}$ 
Sociodemographic characteristics of preadolescents by cardiovascular risk factors $(\mathrm{N}=118)^{\text {a }}$

\begin{tabular}{|c|c|c|c|c|c|c|c|c|c|}
\hline \multirow[t]{2}{*}{ Characteristic, n (\%) } & \multirow[t]{2}{*}{ n (\%) Total } & \multicolumn{2}{|c|}{ Elevated BP n (\%) } & \multicolumn{2}{|c|}{$\begin{array}{l}\text { Being Overweight/ } \\
\text { Obese n (\%) }\end{array}$} & \multicolumn{2}{|c|}{$\begin{array}{l}>2 \text { hrs Screen time } \mathrm{b} / \text { day } \mathrm{n} \\
(\%)\end{array}$} & \multicolumn{2}{|c|}{$<3$ Days PA/Wk n $(\%)$} \\
\hline & & & p-value ${ }^{c}$ & & p-value ${ }^{c}$ & & p-value ${ }^{c}$ & & p-value ${ }^{c}$ \\
\hline n (\%) Total & $118(100.0)$ & $37(31.4)$ & & $48(40.7)$ & & $26(22.0)$ & & $31(26.3)$ & \\
\hline Sex, n (\%) & & & 0.17 & & 0.45 & & 0.66 & & 0.83 \\
\hline Male & $59(50.0)$ & $22(37.3)$ & & $26(44.1)$ & & $14(23.7)$ & & $16(27.1)$ & \\
\hline Female & $59(50.0)$ & $15(25.4)$ & & $22(37.3)$ & & $12(20.3)$ & & $15(25.4)$ & \\
\hline Age group, n (\%) & & & 0.007 & & 0.47 & & 0.33 & & 0.70 \\
\hline $2-5$ years & $46(39.0)$ & $21(45.7)$ & & $18(39.1)$ & & $8(17.4)$ & & $13(28.3)$ & \\
\hline $6-10$ years & $72(61.0)$ & $16(22.2)$ & & $30(41.7)$ & & $18(25.0)$ & & $18(25.0)$ & \\
\hline Mother's education, n (\%) & & & 0.95 & & 0.93 & & 0.10 & & 0.27 \\
\hline$<9$ th grade & $53(44.9)$ & $18(34.0)$ & & $23(43.4)$ & & $12(22.6)$ & & $14(26.4)$ & \\
\hline $9-11$ th & $20(16.9)$ & $6(30.0)$ & & $7(35.0)$ & & $4(20.0)$ & & $2(10.0)$ & \\
\hline High school/GED & $32(27.1)$ & $9(28.1)$ & & $13(40.6)$ & & $4(12.5)$ & & $11(34.4)$ & \\
\hline$>=$ Some college & $13(11.0)$ & $4(30.0)$ & & $5(38.5)$ & & $6(46.2)$ & & $4(30.8)$ & \\
\hline Hispanic Origin, n (\%) & & & 0.57 & & 0.86 & & 0.67 & & 0.19 \\
\hline Mexican-American & $90(76.3)$ & $27(30.0)$ & & $37(41.1)$ & & $19(21.1)$ & & $21(23.3)$ & \\
\hline Other ${ }^{d}$ & $28(23.7)$ & $10(35.7)$ & & $11(39.3)$ & & $7(25.0)$ & & $10(35.7)$ & \\
\hline $\begin{array}{l}{ }^{a} \text { Data from a study of metabolic } \\
{ }^{b} \text { Screen time: includes time watc } \\
{ }^{c} \text { p-value from chi-squared or Fis } \\
{ }^{d} \text { Other Hispanic origin (Puerto- } \\
\text { Abbreviations: BP=Blood Pressu } \\
\text { 3Days PA/Wk=Less than } 3 \text { days }\end{array}$ & $\begin{array}{l}\text { ndrome in Hisp } \\
\text { ng TV and vide } \\
\text { r's exact test } \\
\text { an, Argentine, } \\
\text { GED=Genera } \\
\text { physical activit }\end{array}$ & $\begin{array}{l}\text { umbian, Gu } \\
\text { ducation De } \\
\text { or at least } 6\end{array}$ & $\begin{array}{l}\text { alan, Argen } \\
\text { oment; }>2 \mathrm{hr} \\
\text { lutes per day }\end{array}$ & $\begin{array}{l}\text { Ecuadoria } \\
\text { reen/day }= \\
\text { the past } 7\end{array}$ & $\begin{array}{l}\text { nd El-Salva } \\
\text { ater than an }\end{array}$ & $\begin{array}{l}\text { n) } \\
\text { ge of } 2 \text { hou }\end{array}$ & ratching $\mathrm{T}$ & videos in & 30 days; $<$ \\
\hline
\end{tabular}




\section{Table 2 (on next page)}

Maternal body mass index and physical activity and preadolescents' cardiovascular risk factors $(\mathrm{N}=118)^{\text {a }}$ 
Maternal body mass index and physical activity and preadolescents' cardiovascular risk factors $(\mathrm{N}=118)^{\mathrm{a}}$

\begin{tabular}{|c|c|c|c|c|c|c|c|c|c|}
\hline \multirow[t]{2}{*}{ Characteristic (n \%) } & \multirow[t]{2}{*}{ n (\%) Total } & \multicolumn{2}{|c|}{ Elevated BP n (\%) } & \multicolumn{2}{|c|}{$\begin{array}{l}\text { Being Overweight/ } \\
\text { Obese n }(\%)\end{array}$} & \multicolumn{2}{|c|}{$>2$ hrs Screen b/day n $(\%)$} & \multicolumn{2}{|c|}{$<3$ Days PA/Wk n $(\%)$} \\
\hline & & & $\mathrm{p}$-value ${ }^{\mathrm{c}}$ & & $p$-value ${ }^{c}$ & & p-value ${ }^{c}$ & & p-value ${ }^{c}$ \\
\hline Moderate PA by mother, n (\%) & & & 0.07 & & 0.08 & & 0.551 & & 0.072 \\
\hline Yes & $62(52.5)$ & $13(23.2)$ & & 19(33.9) & & $11(19.6)$ & & $12(19.4)$ & \\
\hline No & $56(47.5)$ & $24(38.7)$ & & $29(46.8)$ & & $15(24.2)$ & & $19(33.9)$ & \\
\hline Mother's BMI, n (\%) & & & 0.15 & & 0.25 & & 0.31 & & 0.003 \\
\hline Normal & $25(21.2)$ & $10(40.0)$ & & $9(36.0)$ & & $7(28.0)$ & & $3(12.0)$ & \\
\hline Overweight & $47(39.8)$ & $10(21.3)$ & & $16(34.0)$ & & $7(14.9)$ & & $8(17.0)$ & \\
\hline Obese & $46(39.0)$ & $17(37.0)$ & & $23(50.0)$ & & $12(26.1)$ & & $20(43.5)$ & \\
\hline
\end{tabular}

${ }^{a}$ Data from a study of metabolic syndrome in Hispanic children at a community health center in Johnson City, TN, June 2015 to June 2016

${ }^{b}$ Screen time: includes time watching TV and videos

c p-value from chi-squared or Fisher's exact test

Abbreviations: $\mathrm{PA}=$ Physical Activity; $\mathrm{BMI}=$ Body Mass Index; $\mathrm{BP}=\mathrm{Blood}$ Pressure; $>2 \mathrm{hrs} \mathrm{TV} / \mathrm{day}=\mathrm{Greater}$ than an average of 2 hours of watching TV or videos in the past 30 days; $<3$ Days PA/Wk =Less than 3 days of physical activity for at least 60 minutes per day in the past 7 days 


\section{Table 3(on next page)}

Bivariate associations between preadolescents' physical activity, screen time, blood pressure and body mass index categories $(\mathrm{N}=118)^{\text {a }}$ 
Bivariate associations between preadolescents' physical activity, screen time, blood pressure and body mass index categories $(\mathrm{N}=118)^{\text {a }}$

\begin{tabular}{|c|c|c|c|c|c|c|}
\hline \multirow[t]{2}{*}{ Characteristic } & \multicolumn{2}{|c|}{ Elevated BP n (\%) } & \multicolumn{2}{|c|}{$\begin{array}{l}\text { Being Overweight/ } \\
\text { Obese n }(\%)\end{array}$} & \multicolumn{2}{|c|}{$<3$ Days PA/WK n $(\%)$} \\
\hline & & p-value & & $\mathrm{p}$-value & & p-value \\
\hline Blood pressure & & & & & & 0.30 \\
\hline Normal & $/ /$ & & // & & $19(23.5)$ & \\
\hline Elevated & // & & // & & $12(32.4)$ & \\
\hline Child BMI & & 0.046 & & & & 0.87 \\
\hline Normal & $17(24.3)$ & & // & & $18(25.7)$ & \\
\hline $\begin{array}{l}\text { Overweight/ } \\
\text { Obese }\end{array}$ & $20(41.7)$ & & // & & $13(27.1)$ & \\
\hline Screen time ${ }^{b}$ & & 0.17 & & 0.85 & & \\
\hline$>2$ hours/day & $26(28.3)$ & & $11(42.3)$ & & // & \\
\hline$<2$ hours/day & $11(42.3)$ & & $37(40.2)$ & & $/ /$ & \\
\hline
\end{tabular}

//: Bivariate association is either not of interest or appear on a different row in this same table

${ }^{\text {a }}$ Data from a study of metabolic syndrome in Hispanic children at a community health center in Johnson City, TN, June 2015 to June 2016

${ }^{\mathrm{b}}$ Screen time: includes time watching TV and videos

Abbreviations: $\mathrm{BP}=\mathrm{Blood}$ Pressure; $\mathrm{BMI}=$ Body Mass Index; $<3$ Days PA/WK=Less than 3 days of physical activity for at least 60 minutes per day in the past 7

1 


\section{Table 4(on next page)}

Odds ratios and $95 \%$ confidence intervals for the associations between maternal body mass index and physical activity and preadolescents' physical inactivity, being overweight/obese, and elevated blood pressure $(\mathrm{N}=118)^{\text {a }}$ 
Odds ratios and $95 \%$ confidence intervals for the associations between maternal body mass index and physical activity and preadolescents' physical inactivity, being overweight/obese, and elevated blood pressure $(\mathrm{N}=118)^{\mathrm{a}}$

\begin{tabular}{|c|c|c|c|}
\hline & $<3$ days of $\mathrm{PA} / \mathrm{WK}$ & Being Overweight or Obese & Elevated BP \\
\hline & $\mathrm{OR}^{\mathrm{b}}(95 \% \mathrm{CI})^{\mathrm{c}}$ & $\mathrm{OR}^{\mathrm{b}}(95 \% \mathrm{CI})^{\mathrm{d}}$ & $\mathrm{OR}^{\mathrm{b}}(95 \% \mathrm{CI})^{\mathrm{c}}$ \\
\hline \multicolumn{4}{|l|}{ Age group } \\
\hline $2-5$ vs $6-10$ years & $0.24(0.04-1.33)$ & $0.90(0.40-2.02)$ & $4.45(1.68-11.78)$ \\
\hline Male vs Female & $0.70(0.27-1.84)$ & $1.32(0.61-2.87)$ & $2.06(0.82-5.21)$ \\
\hline \multicolumn{4}{|c|}{ Mother's Education } \\
\hline \multicolumn{4}{|l|}{$<9^{\text {th }}$ grade (ref) } \\
\hline $9-11^{\text {th }}$ grade & $0.24(0.04-1.33)$ & $0.74(0.24-2.25)$ & $0.75(0.21-2.68)$ \\
\hline High school/GED & $2.44(0.77-7.79)$ & $0.83(0.33-2.13)$ & $0.548(0.17-1.68)$ \\
\hline$>=$ Some college & $1.02(0.21-5.01)$ & $0.83(0.223 .13)$ & $1.14(0.25-5.20)$ \\
\hline \multicolumn{4}{|c|}{ Moderate PA by mother } \\
\hline \multicolumn{4}{|l|}{ yes(ref) } \\
\hline No & $2.92(1.18-7.24) * *$ & $1.77(0.82-3.83)$ & $2.50(1.02-4.53) * *$ \\
\hline \multicolumn{4}{|l|}{ Mother's BMI } \\
\hline \multicolumn{4}{|l|}{ Normal(ref) } \\
\hline Overweight & $1.20(0.28-5.27)$ & na & $0.41(0.13-1.27)$ \\
\hline Obese & $6.47(1.61-26.0)^{* * *}$ & na & $0.70(0.24-2.02)$ \\
\hline \multicolumn{4}{|c|}{$\begin{array}{l}\text { a Data from a study of metabolic syndrome in Hispanic children at a community health center in Johnson City, TN, June } \\
2015 \text { to June } 2016 \\
\text { b adjusted for mother's education, child's age, sex, } \\
\text { c Adjusted for mother's education, child's sex, child age, child BMI, and child PA } \\
\text { Odds ratios were calculated from multiple logistic regression models } \\
\text { Abbreviations: GED=General Education Development; PA=Physical Activity; BMI=Body Mass Index; BP=Blood Pressure; }<3 \\
\text { Days PA/WK=Less than } 3 \text { days of physical activity for at least } 60 \text { minutes per day in the past } 7 \text { days; na=not tested in } \\
\text { multiple logistic regression because alpha of univariate association between variables was }>=0.20 \\
* * \text { p-value }<0.05, * * * \text { p-value }<0.01 * * \text { p-value }<0.05, * * * \text { p-value }<0.01\end{array}$} \\
\hline
\end{tabular}

